\title{
Candesartan inhibits inflammation through an angiotensin II type 1 receptor independent way in human embryonic kidney epithelial cells
}

\author{
YING YU ${ }^{1}$, HAIFENG JIANG ${ }^{2}$, YANGYANG NIU ${ }^{1}$, XIAOQIN ZHANG ${ }^{1}$, \\ YINGYING ZHANG ${ }^{1}$, XI LIU' ${ }^{1}$, TAO QI $^{3}$ and CHEN YU ${ }^{1}$ \\ ${ }^{1}$ Department of Nephrology, Tongji Hospital, Tongji University School of Medicine, 389, Xincun Road, 200065 Shanghai, China \\ ${ }^{2}$ Department of General Surgery, Shuguang Hospital Affiliated to Shanghai University of \\ Traditional Chinese Medicine, 185, Pu'an Road, 200021 Shanghai, China \\ ${ }^{3}$ Division of Anesthesia, The First Affiliated Hospital of Nanjing Medical \\ University, 300, Guangzhou Road, 210029 Nanjing, China \\ Manuscript received on July 10, 2018; accepted for publication on August 30, 2018
}

\begin{abstract}
How to cite: YU Y, JIANG H, NIU Y, ZHANG X, ZHANG Y, LIU X, QI T AND YU C. 2019. Candesartan inhibits inflammation through an angiotensin II type 1 receptor independent way in human embryonic kidney epithelial cells. An Acad Bras Cienc 91: e20180699. DOI 10.1590/0001-3765201920180699.
\end{abstract}

\begin{abstract}
Besides stimulating vasoconstriction, Angiotensin II is also well known in inducing reactive oxygen species and promoting inflammatory phenotype switch via its type 1 receptor. In clinic, Angiotensin II type 1 (AT1) receptor blocker like candesartan has been widely applied as an antihypertensive medication. We previous have demonstrated that a higher dose of candesartan plays a protective role after kidney injury. However, whether candesartan could exhibit anti-inflammatory effects remains unclear. Here, by stimulating isolated human embryonic kidney epithelial cells with tumor necrosis factor- $\alpha$ (TNF- $\alpha$ ), we observed the anti-inflammation capacity of candesartan ex vivo. It was found that pre-treat with candesartan significantly suppressed transforming growth factor- $\beta$ (TGF- $\beta$ ) and interleukin-6 (IL-6) expression after incubation with TNF- $\alpha$. Surprisingly, silence of angiotensin II type 1 receptor has little effects on reducing TGF- $\beta$ or IL- 6 products. Furthermore, candesartan inhibited TNF- $\alpha$-induced oxidative stress in the primary cultured tubular epithelial cells. Overall, our data indicates that candesartan suppresses TNF- $\alpha$-induced inflammatory cytokine production by inhibiting oxidative stress, rather than block AT1 receptor activity.
\end{abstract}

Key words: Angiotensin II type 1 receptor blockers, candesartan, inflammation, reactive oxygen species.

\section{INTRODUCTION}

As the key peptide of renin-angiotensin system (RAS), Angiotensin II (AngII), plays a central role in regulating blood pressure, and maintaining

Correspondence to: Chen $\mathrm{Yu}$

E-mail: yuchen@tongji.edu.cn

ORCid: https://orcid.org/0000-0001-7169-276X

Tao Qi

E-mail: 370753449@qq.com

ORCid: https://orcid.org/0000-0003-2093-4671 electrolyte homeostasis, via the G-protein coupled AngII type 1 receptor (AT1R). Pharmacological blockade of the renin-angiotensin-aldosterone system (RAAS) by AngII type 1 receptor blockers (ARB) and angiotensin converting enzyme inhibitors (ACEI) improves outcomes in patients with renal diseases and cardiac vascular diseases (Zeier 2018, Potier et al. 2017).

It is suggested that renal inflammation also contributes to renal disease progression (Anders 
et al. 2018). Besides stimulating vasoconstriction, Angiotensin II also play key role in inducing reactive oxygen species and promoting inflammatory phenotype switch via its type 1 receptor (Ren et al. 2017, Sifi et al. 2017). ARBs including candesartan are widely used for treating hypertension, chronic heart failure, and diabetic nephropathy by attenuating endothelial dysfunction, reversing oxidative stress, and blocking vascular inflammation (Kageyama 2008, Liang et al. 2016, Xie et al. 2015).

In our previous in vivo study in the model of chronic renal damage of spontaneous hypertensive rat, we found that candesartan was able to suppress NF- $\kappa \mathrm{B}$ activation, tubular chemokines expression, renal inflammation and injury, even if AT1R had already been blocked completely (Yu et al. 2007), suggesting that AT1R-independent mechanisms may be involved in. The present study was designed to determine the AT1Rindependent mechanism of candesartan on its anti-inflammatory effects.

\section{MATERIALS AND METHODS}

\section{CELL CULTURE}

Human embryonic kidney epithelial cells (HKC), bought from ATCC, were cultured in DMEM/F12 medium supplemented with 5\% fetal bovine serum (FBS). Mycoplasma contamination testing was routinely performed. Cells were plated at $\sim 70 \%$ confluence in the medium containing 5\% FBS for 24 hours and then underwent serum starvation for another 24 hours. Human tumor necrosis factor- $\alpha$ (TNF- $\alpha)$ (R \& D SYSTEM, Minneapolis, MN) was added with fresh serum-free medium at a final concentration $(2 \mathrm{ng} / \mathrm{ml})$. At different time points, cell number was estimated by hemacytometer. Cell viability was assessed by Trypan blue exclusion. Cells and conditioned media were harvested for further investigation.

\section{WESTERN BLOTS ANALYSES}

HKC were washed twice with PBS, harvested at a density of $\sim 2 \times 10^{6}$, and were homogenized in RIPA buffer. Protein concentration was assayed with BCA reagents (Sigma, St. Louis, MO). Proteins were separated on SDS-PAGE gel and electrophoretically transferred to polyvinylidene difluoride membranes (Millipore, Bedford, MA). Incubation with monoclonal antibodies for transforming growth factor- $\beta$ (TGF- $\beta$ ), interleukin-6(IL-6), and actin (all from Santa Cruz) was followed by incubation with secondary antibodies coupled to horseradish peroxidase. Antibody binding was visualized using the ECL chemiluminescence system (Amersham). Densitometry was performed using the NIH Image software.

ELISA

The contents of TGF- $\beta$ and IL- 6 in conditioned media from $\mathrm{HKC}$ were determined by specific Quantikine sandwich ELISA kits for human TGF- $\beta$ and IL-6 (R \& D Systems).

\section{CELL TRANSFECTION}

Cells were plated at a density of $2 \times 10^{5}$ cells/well in six-well plates and then transfected with siRNAAT1R or siRNA-control (scrambled sequence) by using Lipofectamine 2000 transfection reagent (Invitrogen, Carlsbad, CA). The transfection mixture was incubated for $25 \mathrm{~min}$ at room temperature. The mixture was evenly applied to the cells. Transfected cells were cultured under normal growth conditions for $48 \mathrm{~h}$ before the experiments. The 21-bp dsRNA sequences were designated as AT1R (5'-GGAGAAAAUGCAUUAUGUGtt-3') directed to nucleotides 135 to 156 . In addition, a scrambled sequence with no nearexact match to any known sequence, Scr (5'-AATGTACTCACTACGAGTGCG -3') was designed as control for AT1R dsRNA. 
DETECTION OF REACTIVE OXYGEN SPECIES (ROS)

Intracellular hydrogen peroxide $\left(\mathrm{H}_{2} \mathrm{O}_{2}\right)$ levels could be evaluated by measuring 2', 7'-dichlorofluroscein (DCF) as reported. Briefly, HKC were pretreated with TNF- $\alpha$, candesartan, candesartan + TNF- $\alpha$ or candesartan $+\mathrm{N}$-acetyl cysteine (NAC, a kind of antioxidant) for 1 hour. Cells were loaded with 10uM of 2', 7'-dichlorodihydrofluorescein diacetate (H2DCF-DA; Molecular Probes, Eugene, OR) for $45 \mathrm{~min}$ at $37^{\circ} \mathrm{C}$. H2DCF-DA is a non-fluorescent, cell membrane-permeable compound that is hydrolyzed to DCF and becomes fluorescent when it is oxidized by $\mathrm{H}_{2} \mathrm{O}_{2}$. Cells were then trypsinized, resuspended in PBS, and the fluorescence was measured with an Flx-800 micro-plate fluorescence reader (Bio-Tek Instruments Inc, Winooski. VT) at the excitation/emission wavelengths of $485 / 528$ $\mathrm{nm}$. Detection was based on mean fluorescence intensity of 10,000 cells.

DATA ANALYSIS

All data were displayed as the mean \pm SD. Statistical analysis of the data from multiple groups was performed by ANOVA followed by StudentNewman-Keuls tests. A probability value of less than 0.05 was considered statistically significant.

\section{RESULTS}

CANDESARTAN SUPPRESSED TNF-A-INDUCED EXPRESSION OF TGF- $\beta$ AND IL-6 IN HKC

To examine the effects of candesartan on cytokine generation, HKC were challenged with TNF- $\alpha$ in the presence or absence of candesartan for 24 h. TGF- $\beta$ and IL- 6 increased significantly in TNF- $\alpha$ stimulated cell. Pretreatment of cells with candesartan significantly reduced TNF- $\alpha$-induced TGF- $\beta$ and IL- 6 compared to control group $(\mathrm{P}<0.05, \mathrm{n}=3)$, with the greatest effect when the concentration of candesartan was $10^{5} \mathrm{M}$ (Fig. 1a, b). The protein production of TGF- $\beta$ and IL- 6 in cultured media, determined by ELISA, was elevated by stimulation of TNF- $\alpha$, and significantly declined with candesartan pretreatment (Fig. 1c, d).

AT1R KNOCKDOWN DID NOT AFFECT

CANDESARTAN SUPPRESSION OF TGF- $\beta$ AND IL-6

To further examine the role of AT1R in the antiinflammatory effects of candesartan, the siRNA method was used to knock down AT1R in HKC. To assess the knockdown efficiency of siRNA, we measured AT1R protein expression by western blotting. In HKC transfected with the specific AT1R siRNA, AT1R protein expression was almost complete suppressed (Fig. 2a, b). In addition, candesartan still markedly suppressed TNF- $\alpha$ induced expression of TGF- $\beta$ and IL- 6 in AT1Rsilenced cells as determined by ELISA (Fig. 2c, d). Similar results were observed in cells transfected with scrambled, inactive siRNA (Fig. 2c, d). This indicated that, AT1R pathway was not involved in candesartan inhibiting TGF- $\beta$ and IL- 6 expression induced by TNF- $\alpha$.

\section{CANDESARTAN BLOCKED TNF- $\alpha$-INDUCED ROS ACTIVATION}

One of the most characteristic aspects of inflammation is the increase in the production of superoxide anion. To assess the potential mechanism of anti-inflammation of candesartan independent on blocking AT1R, we studied the effect of TNF- $\alpha$ and candesartan on oxidative stress. We examined ROS generation in HKC and found that TNF- $\alpha$ significantly increased H2DCF-DA fluorescence, a measurement of ROS generation, compared to untreated control. Pretreatment with candesartan $\left(10^{-5} \mathrm{M}\right)$ or NAC (1 mM) visibly blocked TNF- $\alpha$ induced ROS production (Fig. 3). It seems that candesartan had the similar effect as the antioxidant NAC. 
a

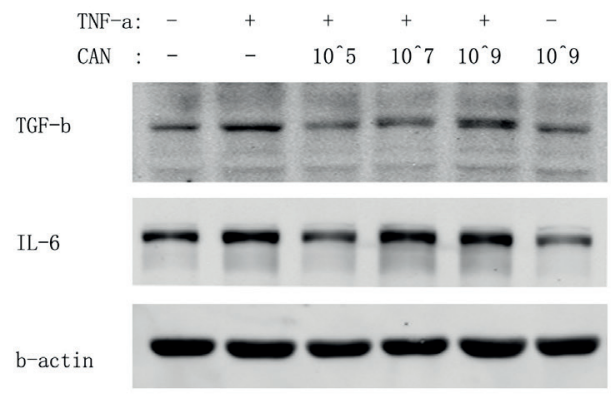

C

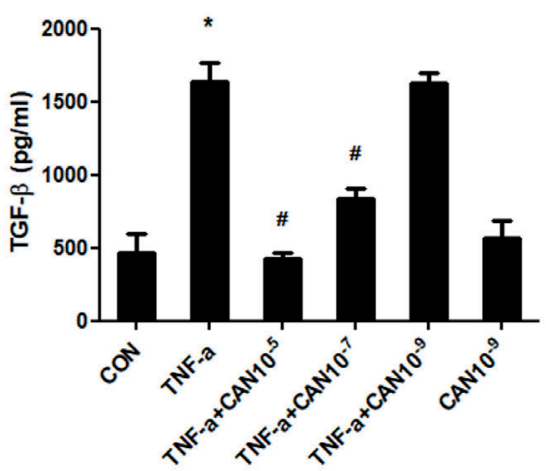

b
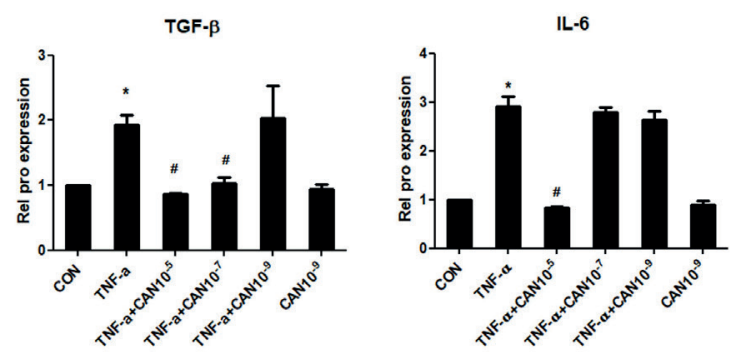

d

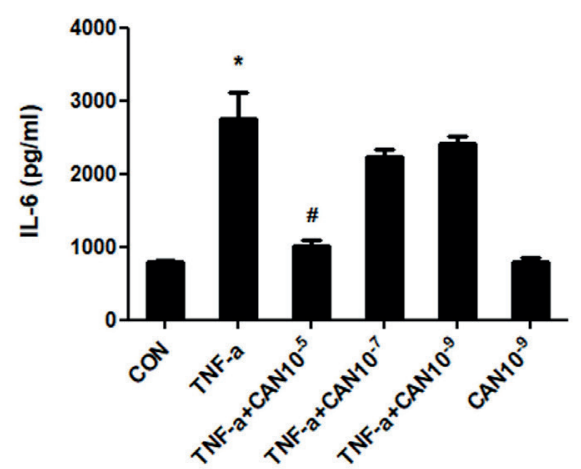

Figure 1 - Candesartan suppresses TNF- $\alpha$ induced expression of TGF- $\beta$ and IL-6. HKC were treated with TNF- $\alpha$ (2ng/ml), or TNF- $\alpha$ combined with different dosages of candesartan for 24 hours. Then cell lysates were prepared and subjected to immunoblot analysis with antibodies to TGF- $\beta$ or IL-6. Representative Immunoblots from three or more experiments are shown (a). Expression levels of the indicated proteins were quantified by densitometry and normalized with $\beta$-actin (b). Conditional media from cultured cells were collected and TGF- $\beta$ (c) or IL-6 (d) levels were determined by ELISA ( $\mathrm{n}=3)$. $\mathrm{P}<0.05$ vs. CON, \#P<0.05 vs. TNF- $\alpha$ treatment; CON: control, CAN: candesartan.

\section{AT1R KNOCKDOWN DID NOT AFFECT CANDESARTAN SUPPRESSION OF ROS ACTIVATION}

In cells which were transfected with control siRNA, TNF- $\alpha$ significantly increased H2DCF-DA fluorescence, that is ROS production, and pretreatment with candesartan markedly blocked TNF- $\alpha$ induced ROS production. After knockdown AT1R with siRNA, candesartan still depressed TNF- $\alpha$ induced ROS production significantly (Fig. 4).

\section{DISCUSSION}

Renal inflammation is the most central factor in the process of chronic renal fibrosis and end stage renal disease. ARBs have been reported to reduce inflammation in diabetic rat, and cardiac diseases via a variety of mechanisms including reducing oxidative stress and improving endothelial dysfunction (Kageyama 2008). Clinical studies have suggested that treatment with candesartan leads to decreased plasma levels of C-reactive protein, TNF- $\alpha$, interleukin- 6 , soluble intercellular adhesion molecule-1, and soluble vascular cell adhesion molecule-1 in patients with mild to moderate chronic heart failure and hypertension (Koh et al. 2006, Grosso et al. 2011). In these previous researches, the mechanisms of anti- 
a

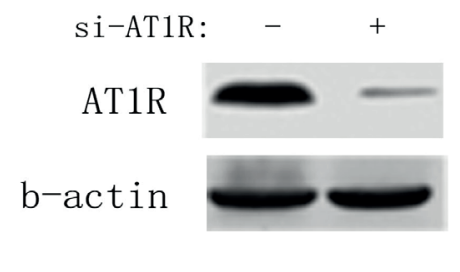

C

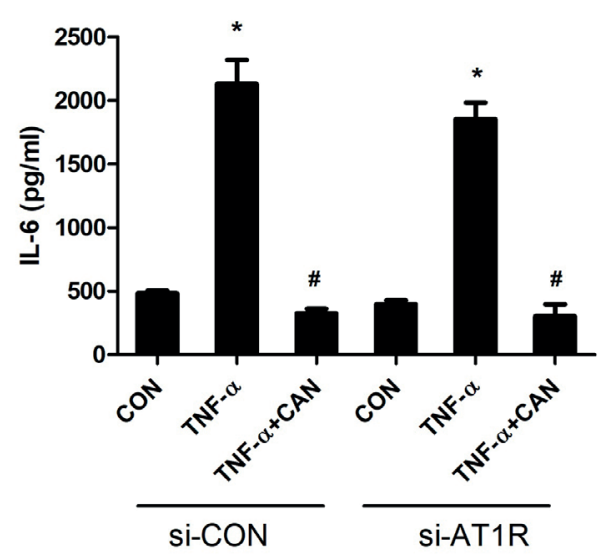

b
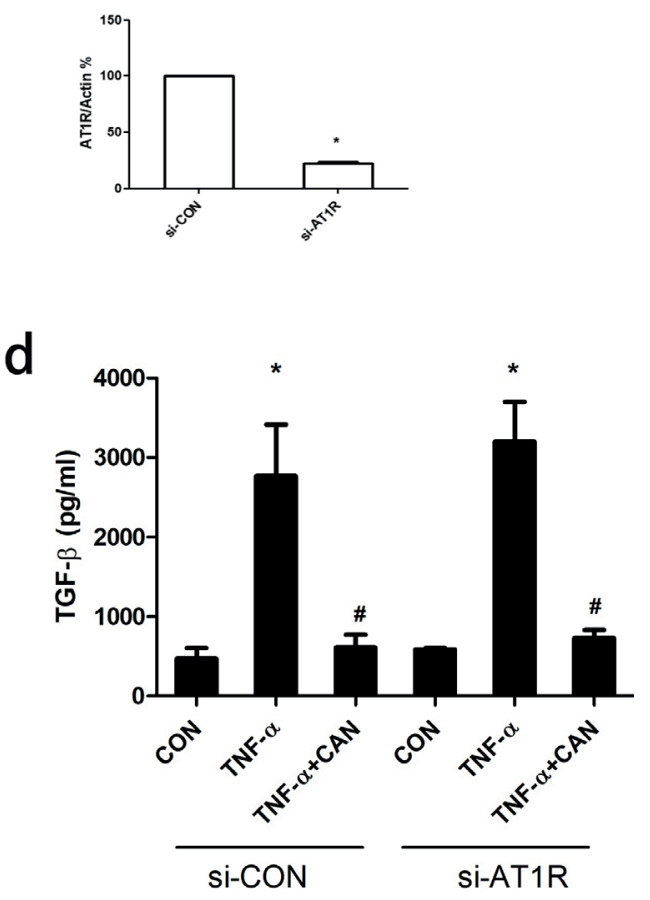

Figure 2 - Knockdown of AT1R did not affect candesartan suppression of TGF- $\beta$ and IL- 6 induced by TNF- $\alpha$. HKC were transfected with AT1R siRNA or scrambled siRNA（100nM） for 24 hours. Then cell lysates were immune-blotted with anti-AT1R antibody (a, b). After transfection, cells were treated with TNF- $\alpha(2 \mathrm{ng} / \mathrm{ml})$ along or TNF- $\alpha$ combination with candesartan $\left(10^{-5} \mathrm{M}\right)$ for 24 hours. Conditional media from cultured cells were collected and TGF- $\beta$ (c) or IL-6 (d) levels were determined by ELISA ( $n=3)$. $* \mathrm{P}<0.05$ vs. $\mathrm{CON}, \# \mathrm{P}<0.05$ vs. TNF- $\alpha$ treatment; $\mathrm{CON}$ : control, CAN: candesartan.

inflammation of high-dose ARB was mainly thought to be: 1) the expression of angiotensin receptor are increased in pathologic condition, so that the routine dose of ARB could not bloke AT1R completely and higher dose of ARB was needed. 2) The anti-inflammatory effect of ARB acted mainly through blocking AT1R and suppressing AngIIinduced ROS production (Yu et al. 2007, Kondo et al. 2006).

Interestingly, our previous in vivo research showed high-dose candesartan had an antiinflammatory effect, and even though AT1R was already blocked completely. This indicated there might be AT1R independent-pathway involved, but the exact mechanism was not known. In the present

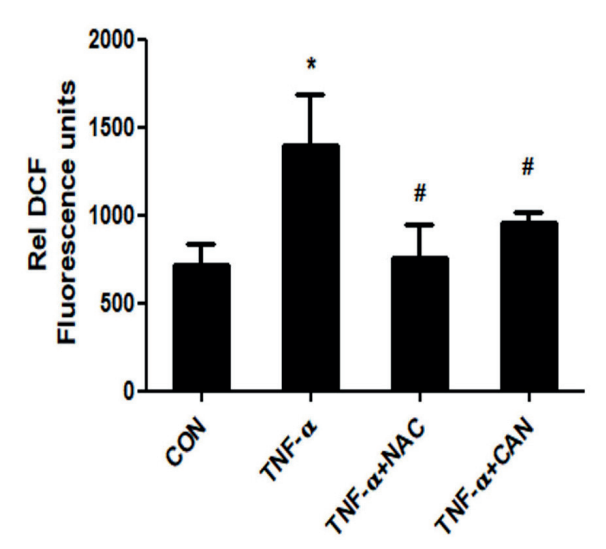

Figure 3 - Candesartan inhibits of ROS generation induced by TNF- $\alpha$. HKC cells were treated with TNF- $\alpha(2 \mathrm{ng} / \mathrm{ml})$ along or TNF- $\alpha$ combination with candesartan $\left(10^{-5} \mathrm{M}\right)$ or NAC (1 $\mathrm{mM})$ for 24 hours. Then cell lysates were collected to measure ROS generation by DCF fluorescence assay. $\mathrm{n}=3$. ${ }^{*} \mathrm{P}<0.05$ vs. $\mathrm{CON}, \# \mathrm{P}<0.05$ vs. TNF- $\alpha$ treatment; $\mathrm{CON}$ : control, $\mathrm{CAN}$ : candesartan. 


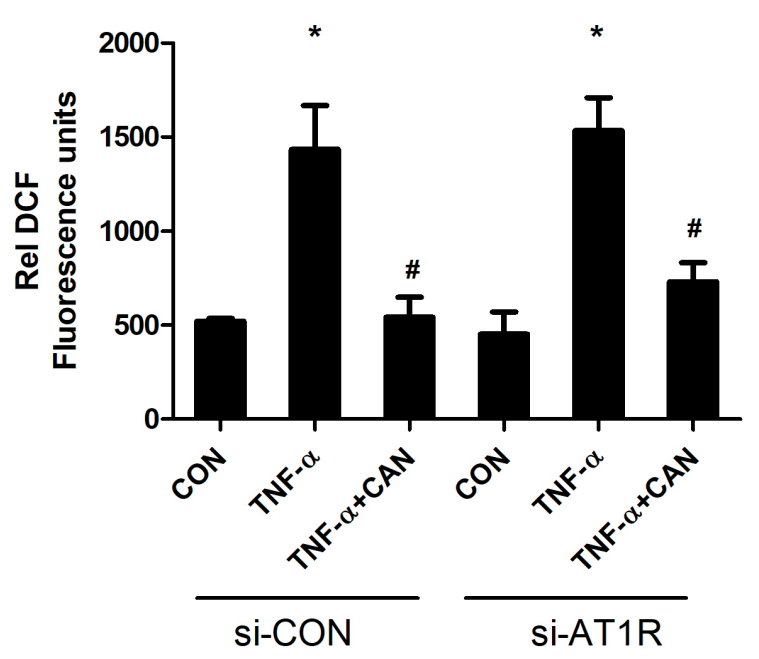

Figure 4 - Candesartan blunts TNF- $\alpha$ induced ROS production. HKC were transfected with AT1R siRNA or scrambled siRNA. 24 hours later, cells were treated with TNF- $\alpha(2 \mathrm{ng} / \mathrm{ml})$ along or TNF- $\alpha$ combination with candesartan $\left(10^{-5} \mathrm{M}\right)$ for another 24 hours. Cell lysates were collected to measure ROS generation by DCF fluorescence assay. $\mathrm{n}=3 .{ }^{*} \mathrm{P}<0.05$ vs. $\mathrm{CON},{ }^{*} \mathrm{P}<0.05$ vs. TNF- $\alpha$ treatment; CON: control; CAN: candesartan.

study, we showed that candesartan markedly inhibited inflammatory mediators TGF- $\beta$ and IL-6 induced by TNF- $\alpha$ in HKC in a dose-dependent manner, and that silencing of AT1R by RNA interference did not affect candesartan inhibition of TGF- $\beta$ and IL-6. These observations are consistent with the notion that the anti-inflammatory effects of candesartan are independent of blockade of the AT1 receptor, at least, in part.

ROS are important signaling molecules that modulate gene transcription via the activation of redox-sensitive protein kinases and transcription factors. A number of pro-inflammatory stimuli, including TNF- $\alpha$, are known to induce the production of ROS (Haas et al. 2015, SantabarbaraRuiz et al. 2015). The present study showed that candesartan blunted the increase of ROS production induced by TNF- $\alpha$, essentially equivalent to the antioxidant NAC. Further, knockdown AT1R did not change candesartan depression of ROS activity. These results provide evidence that candesartan may play a direct antioxidant role.
In conclusion, we suggested that the novel mechanism of candesartan was attributable to decreasing inflammation by reducing ROS generation as a direct antioxidant. Our findings may have pathophysiological and clinical implications for patients with chronic kidney disease, because these patients were often with enhanced ROS production, which leading to inflammation via increased expression of inflammatory mediators such as TGF- $\beta$ and IL-6. Although these novel findings need to be confirmed in patients, we propose that the documented pleiotropic antiinflammatory effect of ARBs such as candesartan is mediated, in part, via the non-AT1R pathway.

\section{ACKNOWLEDGMENTS}

This study was supported by grant of National Natural Science Foundation of China to C. Yu (81370790), National Natural Science Foundation of China to Ying Yu (81600523), and National Natural Science Foundation of China to Xi Liu (81700617).

\section{AUTHOR CONTRIBUTIONS}

YY: Conception and design of research, performed experiments, analyzed data, interpreted results of experiments, edited and revised manuscript, approved final version of manuscript. HJ: Performed experiments, analyzed data, interpreted results of experiments, approved final version of manuscript. YN, XL: Performed experiments. XZ: Analyzed data. YZ: Edited and revised manuscript. CY: Conception and design of research, interpreted results of experiments, edited and revised manuscript, approved final version of manuscript. TQ: Edited and revised manuscript, interpreted results of experiments, approved final version of manuscript. YY and HJ contributed to this work equally. 


\section{REFERENCES}

ANDERS HJ ET AL. 2018. The macrophage phenotype and inflammasome component NLRP3 contributes to nephrocalcinosis-related chronic kidney disease independent from IL-1-mediated tissue injury. Kidney Int 93: 656-669.

GROSSO AM, BODALIA PN, MACALLISTER RJ, HINGORANI AD, MOON JC AND SCOTT MA. 2011. Comparative clinical- and cost-effectiveness of candesartan and losartan in the management of hypertension and heart failure: a systematic review, meta- and cost-utility analysis. Int J Clin Pract 65: 253-263.

HAAS B, CHRUSCIEL S, FAYAD-KOBEISSI S, DUBOIS-RANDE JL, AZUAJE F, BOCZKOWSKI J, MOTTERLINI R AND FORESTI R. 2015. Permanent culture of macrophages at physiological oxygen attenuates the antioxidant and immunomodulatory properties of dimethyl fumarate. J Cell Physiol 230: 1128-1138.

KAGEYAMA S. 2008. Clinical trials of ACE inhibitors and ARB for treatment of patients with hypertension, heart failure, and diabetic nephropathy in Japan - special reference to the dosage schedule and adverse effects. Nihon Yakurigaku Zasshi 131: 180-181.

KOH KK, QUON MJ, HAN SH, CHUNG WJ, LEE Y AND SHIN EK. 2006. Anti-inflammatory and metabolic effects of candesartan in hypertensive patients. Int J Cardiol 108: 96-100.

KONDO S ET AL. 2006. Addition of the antioxidant probucol to angiotensin II type I receptor antagonist arrests progressive mesangioproliferative glomerulonephritis in the rat. J Am Soc Nephrol 17: 783-794.

LIANG DL, LI XY, WANG L, XU H, TUO XP AND JIAN ZJ. 2016. Current status and influence factors of ACEI/ARB application in elderly coronary heart disease outpatients complicated with diabetes mellitus in China. Zhonghua Yi Xue Za Zhi 96: 2917-2922.

POTIER L ET AL. 2017. Angiotensin-converting enzyme inhibitors and angiotensin receptor blockers in high vascular risk. Heart 103: 1339-1346.

REN XS ET AL. 2017. NLRP3 Gene Deletion Attenuates Angiotensin II-Induced Phenotypic Transformation of Vascular Smooth Muscle Cells and Vascular Remodeling. Cell Physiol Biochem 44: 2269-2280.

SANTABARBARA-RUIZ P, LOPEZ-SANTILLAN M, MARTINEZ-RODRIGUEZ I, BINAGUI-CASAS A, PEREZ L, MILAN M, COROMINAS M AND SERRAS F. 2015. ROS-Induced JNK and p38 Signaling Is Required for Unpaired Cytokine Activation during Drosophila Regeneration. PLoS Genet 11: e1005595.

SIFI A, ADI-BESSALEM S AND LARABA-DJEBARI F. 2017. Role of angiotensin II and angiotensin type-1 receptor in scorpion venom-induced cardiac and aortic tissue inflammation. Exp Mol Pathol 102: 32-40.

XIE Q, HAO CM, JI L, HU D, ZHU T, LI X, QIN D AND ZHANG D. 2015. ACEI/ARB underused in patients with type 2 diabetes in Chinese population (CCMR-3B study). PLoS ONE 10: e0116970.

YU C, GONG R, RIFAI A, TOLBERT EM AND DWORKIN LD. 2007. Long-term, high-dosage candesartan suppresses inflammation and injury in chronic kidney disease: nonhemodynamic renal protection. J Am Soc Nephrol 18: 750-759.

ZEIER M. 2018. ACE Inhibitors and ARB in Chronic Kidney Disease: What Has to Be Considered. Dtsch Med Wochenschr 143: 880-885. 